\title{
Research about mechanics theory and damage mechanism of asphalt pavement design
}

\author{
Xiaochun Zhang ${ }^{1, \text { a }}$, Yiqing Liu ${ }^{1, b}$ and Yingzhou Yan ${ }^{1, \mathrm{c}}$ \\ ${ }^{1}$ Intelligent Transportation System Engineering Research Center, Southeast University, Jiangsu, \\ Nanjing 210096, China \\ azxc01@263.net>", bseulyq@163.com, 595227811@qq.com c
}

\begin{abstract}
Keywords: Asphalt pavement; Constitutive relation; Numerical analysis; Experimental research
Abstract: Asphalt pavement is the main pavement pattern in China. There have been a serious of achievements over the past decades in mechanics theory and damage mechanism of asphalt pavement. Based on the above two aspects in asphalt pavement design, this paper provides a detailed overview of the application of mechanic theory, evolution of constitutive relation, numerical analysis and experimental study.
\end{abstract}

\section{Introduction}

Asphalt pavement plays a significant role in road pavement in China, accounting for above $75 \%$ of the total highway. Unfortunately, as the development of road transportation, Great changes have happened in road transportation structure. For example, the characteristics of "heavy trucks, high flow and channel traffic" have appeared in road transportation in resent years, which have leaded to pavement early damage with varying degree. As a result, many aspects, such as road service life, service level, operational efficiency, traffic safety, environment protection and road management, have been impacted by this phenomenon.

The study about the design philosophy, design method and damage mechanism in asphalt pavement design have attracted scholars' and engineers' attention in the past decade. A serious of studies in this field have been lanched and many achievements have been obtained. This paper aims to outline the researches of mechanics theory and damage mechanism of asphalt pavement from the aspects of mechanic theory, material constitutive relation, numerical analysis and experimental research.

\section{Study of mechanic theory and damage mechanism in asphalt pavement design}

The asphalt pavement design theory is closely related to mechanic theory. The asphalt pavement design has gone through the process from apparent phenomenon to stress mechanism analysis. In other words, the process is from the traditional empirical method to simple strength theory, and then to the current modern mechanics.

\section{Traditional empirical method}

In early days, based on the survey data of different road type, empirical formula and method were summarized through the analysis of data collected. Then, the life of asphalt pavement could be predicted based on pavement structure damage with the empirical formula obtained. After the analysis of asphalt pavement structure with currently knowledge, the pavement design methods were appropriately proposed.

\section{The application of strength theory}

Material strength theory has been widely used in early and modern asphalt pavement design duo to asphalt pavement crack, rutting and other damage phenomena. For example, in current rigid pavement design, the max stress at the bottom of board is used to check the strength with flexural strength of trabecular as a comparison standard. In flexible pavement design in China, the same strength theory is used for checking the bottom of asphalt concrete layer in the spring melt. The max 
strain at the bottom of flexible pavement as checking standard is used by Royal Dutch Shell method. The max strain energy method is appropriate to check the brittle cracking at the bottom of pavement, as well as the compress soil under the pavement. Tensile pressure with vary performance is considered in Moore strength. So it can be applied for the road surface damage analysis duo to shear slip and grass or based strength checking. [1]

Strength theory and material strength indicator is determined by a variety of tests and field data. It is highly related to the engineering practical experience and calculated methods and parameters based on the experience.

\section{The application of modern mechanics theory}

\section{Theory of plasticity and fatigue strength}

With the development and application of plasticity mechanics and strength theory, the research about asphalt pavement damage becomes into a rational analysis stage [2,3].

Ensuring sufficient bearing capacity of structure is the mainly application for plasticity in road design. In other words, by using the shear strength indicators and plastic failure theory, the yield damage of structure is analyzed in order to avoid the appearance of such damage. Based on the previous field tests conducted by AASHO, the importance of improving the structure cohesion is certified by using plasticity. Two aspects of cohesion (C) and internal fraction ( $\varphi$ ) should be considered to ensure the bearing capacity of structure in pavement design based on the above theory. While in practice, merely improving one aspect often happen in engineering, which may lead to inappropriate measures and adverse consequences.

With the development of fatigue damage theory, it is recognized the reason why road damage occurs is that the fatigue stress caused by repeated load overheads the tensile stress of pavement material. According to ten years of extensive tests, great reforms in pavement design with fatigue theory have happened in United States, Britain, the Soviet Union, West Germany and other countries. Moreover, in current asphalt pavement design, this design method based on fatigue theory is used by many countries $[4,5,6]$. However, for different country, different specific design method is adopted duo to varying situation.

\section{Fracture mechanics}

In fatigue strength theory, the reason why material destruct is the cumulative damage happened in material duo to repeated loads. However, the analysis is based on continuous, complete architecture without deflects, instead of the structure considering inherent deflects or deflects duo to usage of structure which may lead to adverse effect on pavement structure. Consequently, there is a deviation between the result of asphalt pavement design using fatigue theory and the reality. Despite the introduction of different correction factors or safety factors, the design results still have a large degree of uncertainty. However, fracture mechanics can compensate for this deficiency in some extent. From the perspective of fracture theory, the structure has inherent defects and under the effect of loads these defects will lead to local strength concentration and inherent injury. Then cracks appear and the growth, expansion and joint of these cracks ultimately cause the structural damage. With the improvement, development and the application of fracture theory, the evolution of pavement design will or is happening.

In the analysis of asphalt pavement structure by using fracture theory, it is generally acknowledged the crack always has width and the curvature of crack tip is not zero. Moreover, stress concentration is considered at seams and traditional strength theory is used to do calculation. By using thermal elasticity method, Monismith[7,8] studied the stress distribution of crack subgrade base (or old roads) and asphalt overlay under traffic loads and temperature loads as well as the dissipate analysis of stress concentration near the top of the crack tip in rubber asphalt interlayer. The result has shown that the soft interlayer can effectively reduce the stress concentration at crack tip and slow the expansion of reflective cracks. Many researchers such as Coetzee, Francken and Marchard [910,11,12] el at also 
have done the similar analysis. The study of Francken[10] have shown that the stiffness of interlayer material is positive related to the effect of crack prevention. Moreover, the low bonding strength of interlayer may lead to the extension of cracks along the interface in base layer or old roads while the high bonding strength of interlayer will not cause degumming phenomenon and crack will expand vertically. By using Finite Element Analysis, Leslie et.al[13,14,15] explain why tension stress concentration is the main factor of crack expansion in the tip of crack and then analyze the development mechanism of longitudinal crack in the surface. Besides, the expansive direction and stress strength factor are predicted through the change of design parameters of pavement structure and the relative position between loads and cracks. Zhenhua Jiang[14,15] studies the relation between the J integral at the points around surface crack tip and the crack positions, loads' patterns and pavement structural parameters based on actual small cracks of pavement surface. Rui Luo[16,17] obtained the calculated method of stress strength factor of surface crack by using weight function theory and corresponding computer program is also obtained. The conclusion is that the tire pressure and horizontal force have great influence on stress strength factor.

Moreover, to investigate the extension law of crack in semi-rigid base under transit and temperature loads and the measures of preventing cracks, systematic researches are conducted using linear elastic fracture mechanics theory and methods by Zhang Qisun[18], Liu Yihe[19], Zheng Jianglong[20], Wu Ganchang[21], Zhou Zhigang[22] and so on.

\section{Fatigue Fracture Mechanics}

Because asphalt pavement structure is affected by transit and temperature loads, the damage of pavement is always characterized by fatigue damage. The study of asphalt pavement fatigue damage can be divided into two phases, namely the traditional fatigue crack without deflects phase and the phase considering fatigue fracture of crack. For the former, lots of tests, analysis and experience have been done by researchers and the results archived are still used in current pavement structural design. In regard to the latter, the studies are mainly about the regularity of fatigue cracking.

Currently, the empirical formula Paris is commonly used when the fatigue fracture mechanism and method are used to analyze pavement fatigue crack $[23,24]$. The pattern of cracks in asphalt pavement structure is complex under the transit and temperature loads [25]. Consequently, there is a deviation between the formula Paris obtained by crack fatigue experiments and the reality. This mainly is reflected on the number of items in the formula describing expansion rate of fatigue cracking and parameters in the model.

It has been found that it is properly to use Schapery theory to study the fatigue crack expansion process of asphalt concrete and its structure duo to the asphalt properties of temperature sensitivity and thermal viscoelasticity [26]. The Schapery theory is based on formular Paris and use the viscoelastic properties of asphalt to predict two parameters $(A, n)$ in formular Paris. Lately, modified formular used to calculate fatigue fracture parameters in Schapery theory is got by many crack tests of different asphalt concrete $[27,28,29]$.

Asphalt pavement crack can be analyzed by fatigue mechanism [38, 30,31,32]. Then, some valuable conclusion will obtained, which can provide guidance for practice and propose design formula of asphalt overlay [28, 33,34,35]. The study of asphalt pavement fatigue crack is still a hot topic currently duo the complexity of asphalt concrete property.

\section{Mechanics of visco-elastic fracture damage}

Asphalt has the properties of temperature sensitivity and viscoelastic at certain temperature. Meanwhile, because asphalt is organic material with great molecular chains and the chains have the function of connecting again after breaking, the damage crack od asphalt have timeliness property. The properties above of asphalt provide a platform for studying the damage mechanism of asphalt pavement using mechanics of visco-elastic fracture damage. 
To evaluate the development and healing of asphalt pavement damage under repeated loads, Lytton el at[36] have built a continuum damage model based on elastic-viscoelastic criterion and potential function. The damage development of asphalt concrete under single load with varying stress rate as well as the damage development and healing duo to complex loading history were predicted successfully by this model. Scapas el at[37] analyzed the mechanics of generation and expansion of fatigue damage of asphalt pavement surface under different type of loads by the combining methods of tests and theoretical analysis and conducted Finite Element Analysis. Kim[38] analyzed the causes of pavement early damage by using viscoelastic continuum damage model and evaluated the effect of mix and test conditions on fatigue performance. Actual performance data of test sections was used to verify the section fatigue performance predicted by viscoelastic continuum damage model and models with varying simplified levels were evaluated. Then, simplified method of fatigue cracking test was evaluated.

Nilsson [39] evaluated material model currently used to predicted the life of asphalt pavement as well as different continuum damage mechanic model. Then, he compared the evaluated results to previous models.

Shalaby el at [40] assessed pavement damage conditions by using continuum damage mechanic theory. They did the laboratory test of asphalt pavement specimens got from site and compared damage indicators of asphalt concrete at low temperature, such as stiffness modulus, dissipated energy and tensile stress.

Tuskegee [41] proposed a new method of analyzing fatigue expansion property of asphalt concrete and developed the relationship between fatigue crack expansion of pavement and micro-structure and construction process, which was helpful to improve life of pavement and preventing pavement cracks.

Zheng Jianlong, Tang Xuesong, Zhou Zhigang also have done a lot of work in the study of the theory of viscoelastic damage $[42,43,44,45,46]$.

\section{Study of material constitutive relation}

Asphalt concrete is temperature sensing composite material with complex structure and components. To solve the problems in road design, a variety of constitutive relation model were proposed by scholars based on lots of tests and continuum mechanics. Currently, constitutive relation models are no less than dozens, but they can be divided into the following categories.

\section{Constitutive relation based on elastic theory}

Currently, Duncan-Chang nonlinear elastic model is used to describe stress-strain relation of asphalt concrete in domestic [47,48]. Jiaji Feng[49], Weibiao Wang[50] and Zhiqiang Li[51] respectively propose some improvements for the Duncan-Chang model. It suggests that hyperbolic relation is only appropriate to stress-strain relation of concrete in middle stress area instead of high and low stress area. Strength envelop of asphalt concrete changes nonlinearly with the increase of lateral pressure. The nonlinear law of strength envelop suggests that the strength theory of asphalt concrete do not meet Moor-Coulomb theory.

\section{Constitutive relation based on elastic-plastic theory}

To evaluate the safety of highway subgrade base, US. Federal Highway Administration (FHWA) has started a plan to research the constitutive relation of subgrade base soil. One of the results is MAT-147 constitutive relation model. It regards soil as homogeneous isotropic medium and elastic-plastic model is used to describe elastic and plastic deformation. This model eliminates two major drawbacks of before improvement of the model by changing the Mohr-Coulomb yield condition used in this model. Because the mechanical property of soil is highly related to soil porosity and moisture content, the effect of pore ratio and pore water pressure is introduced into constitutive relation model. Besides, as the stress-strain curve becomes steep with increasing loading rate, the effect of strain rate is also considered in this model [52]. 


\section{Constitutive relation based on viscoelastic theory}

Duo to thermal viscous characteristic of bitumen, asphalt exhibits viscoelastic behavior at certain temperature. One-dimensional nonlinear viscoelastic constitutive equations [55], such as Burgers model [42, 56], Maxwell model[53, 54] and generalized Maxwell model and improved Burgers model [57] are used to describe the rheological properties of asphalt concrete under different temperature.

\section{Constitutive relation based on viscoplastic theory}

As the development of constitutive relation of asphalt concrete, visco-plasticity of asphalt concrete increasingly become the focus of researchers' attention. Drucker-Prager yield function is extensively used to describe the behaviors of confining pressure, aggregate fraction, interlock and expansion in asphalt and other geological materials [60,61]. Laith Tashman el at[62] amended Prager yield function by using micro viscoplastic continuous constitutive model and adding the effect of anisotropic aggregate and the expansion process of cracks and holes. Based on Desai model [59], Erkens[58] proposed ACRe model with three dimensional yield surface, which can describe the state and soften hardened state of asphalt concrete. Vassilis[63] proposed a super-elastic - viscoplastic constitutive model, which could describe the characters of volume tensor and partial tensor of asphalt concrete under shear loads. In the viscoplastic model, anisotropy of aggregate was considered and stress invariant was amended. Yield function was proposed to describe the effect of soft behavior, anisotropy and damage by introducing the damage variances to describe damage influence in effective stress theory. Krishnan[64] proposed hybrid constitutive relation by regarding asphalt concrete as ideal fluid after ignoring the influence of temperature and chemical reaction. He also assumed that the constitutive relation of each component of mixture only depended on momentum of component ignoring the plastic deformation of asphalt concrete. It is effective for this model to solve problems, such as pavement weeping, permeability and porosity reduction of asphalt pavement.

\section{Numerical simulation and experimental study}

\section{Numerical simulation}

Some mechanical problems about asphalt pavement design have been received in-deepth study with the rapid development of computer technology, which provides a scientific basis for pavement design and checking.

In terms of constitutive relation of numerical simulation, the mechanic analysis of pavement structure has developed from the period of elastic analysis to the current period of elastic-plastic analysis, visco-elastic analysis and visco-elastic-plastic analysis. Then, the elastic response [65], plastic response [67] and response timeliness [68] of pavement structure are analyzed.

In terms of contents of numerical simulation, the analysis of pavement structure has developed from the period of stress analysis to the period of fatigue analysis [67,68], crack analysis $[14,15,20]$, fatigue damage performance of pavement $[74,75]$ and life prediction analysis [76,77].

In terms of loading condition of numerical simulation, the analysis has been changed from static, quasi-static analysis to dynamic analysis [66].

Moreover, the boundary element method and discreet element method have also been used extensively in the structure analysis of pavement. Based on the characteristic of boundary element method, Xiaoming Huang [69] has proposed a calculation method to solve stress of layered system. Through combining the layered material fundamental solution with boundary element methods Qiang Yue, Fusheng [70] Liu et al created the boundary integral equation in flexible layered pavement. They proposed stress and displacement boundary element method in layered asphalt pavement.

On the basis of considering the performance on fatigue damage restoration, Jun Chen et al [71] established pavement structure model through discrete element method. They also analyzed the force 
characteristics of the bottom layer of asphalt pavement structure under sinusoidal force repeated loads.

Also, discrete element method has been applied in the performance simulation of the internal structure of asphalt mixture. O'Sullivan C, Buttlar et al [72,73] has simulated the mechanical properties of the mixture internal structure using discrete element.

\section{Experimental Study}

Due to the lack of asphalt concrete fatigue fracture parameters, the result is not accurate when using fatigue fracture mechanics to predict fatigue cracking life. Therefore, researchers have launched a series of studies on the performance of asphalt concrete fatigue fracture and damage. The research in this area can be divided into two categories:

(1) Obtain the fatigue damage parameter of relevant materials should be obtained firstly $[38,39,40,41,42]$. For example, using a common evolutionary models and classical damage theory of fatigue damage, Zhigang Zhou [46] has obtained the asphalt mixture fatigue damage parameters of direct tension, cantilever bending, three points bending of beam specimen and APA round wheel load. Hongxin Guan [78] identified the asphalt viscoelastic parameters and stress levels of indoor direct tension fatigue test using indoor stress fatigue test method. Besides, through conducting asphalt mixture fatigue damage test under different conditions, he has obtained viscoelastic parameters of fatigue damage model.

(2) Discuss the existing experimental methods. Currently, test methods about asphalt concrete fracture properties and fatigue fracture performance contains direct tensile test (DT), indirect tensile test (IT), four-point flexural tensile test (4PB), three-point bending tensile test (3PB) and try semicircle the flexural test (SCB). Rosier et al [25], who conducted three-point bending test, pointed out that the split end cracking state is type I and type II coexist state. Because the difference in the proportion of the share of the relevant shear, the fatigue fracture parameters in Paris Formula are not consistent with that in type I. Krans et al [79] used DT and 4PB to conduct fatigue fracture test on a so-called micro-dense material concrete. Result showed that the crack growth rate is almost independent of frequency and load, and the effective stress intensity factor has relation with cyclic stress ratio.

\section{Conclusion}

This paper reviews the progress of asphalt concrete pavement design theory and research on damage mechanism. Due to temperature sensibility and structure complexity of asphalt concrete, the application of modern mechanics has a wide range of prospects. For example, as the description of constitutive relations under different temperatures involves elastic - plastic - viscoelastic conversion, so it needs an urgent in-depth research. Besides, because the asphalt concrete itself is a defect-rich composite material, therefore self-healing mechanism of the damage is also the focus of current research. Researchers also need to take effort to study the relationship between macroscopic mechanical properties and microscopic damage of asphalt concrete, to study the injury mechanism between cement and aggregate body. It is believed that, through in-depth study of asphalt concrete physical, mechanical and chemical properties, Mechanic-experience method of asphalt concrete pavement design will become more scientific and the development of physical, mechanical and chemical disciplines also will have a new platform.

\section{References}

[1] Zhu Zhaohong, Wang Binggang, Guo Dazhi. Road Computational Mechanics[M].Beijing: People's Communications Press.1985 (9), 9 -10. 
[2] Translation by Road and Bridge Department in Northeast Forestry University. Modern road pavement design [M]. Beijing: People's Communications Press.1984.

[3] Translation by Wupei Yu, Yang Jiaqi. Translation pavement design [M] Beijing: People's Communications Press. 1987.

[4] AASHTO.Guide for design of pavement structure.1994.

[5] Ministry of Communications(JTJ014-97). Specifications for design of highway asphalt pavement. Beijing: People's Communications Press. 1997.

[6] Ministry of Communications(JTJ012-94). Specifications for design of highway cement concrete pavement. Beijing: People's Communications Press. 1994.

[7] N.F.Coetzee, C. L. Monismith. Analytical Study of minimization of reflection cracking in asphalt concrete overlays by use of a rubber-asPahltinterlayer.1981, TRR700:101-108.

[8] C.L.Monismith, N.F.Coetzee. Reflection Cracking: Analysis, Laboratory State and design Considerations. In: Proeeedings of AAPT, 1980, 49:268-313.

[9] N.F. Coetzee. Some considerations on Reflection cracking in Asphalt Concrete eoverlay Pavement. (Ph.D. Dissertation) California: Univ. of California, 1979.

[10]L.Francken.A.Vanelstraete. Interface Systems to Prevent Reflective Cracking: Modelling and Experimental Testing Methods. In: Proceedings of the 7th OSAP,1992,1:45-60

[11]J.P. Marchand, H.Goacolou. Cracking in Wearing Course. In: Proceedings of 5th ISAP, 1982:741-757.

[12] A. Vanealstraete, L. Fanken. Numercial Modelling of Crack Initiation under Thermal Stress and Traffic. In: Proceedings of the 2th Int. RILEM Conf.1993:136-145.

[13]Leslie add Myers, Reynaldo Roque and Bjorn Birgisson,PROPAGATION MECHANISMS FOR SURFACE-INITIATED LONGITUDINAL WHEEL PATH CRACKS[c], 2001 TRB Annual Meeting, Paper No. 01-0433

[14]Jiang Zhenhua.,Zhang Xiaochun, Research on the Law of Surface Crack Propagation in Asphalt Pavement[J].Wang Jun.Modern Transportation Technology.2006.

[15]Jiang Zhenhua.Time-related research on surface Crack Propagation Behavior in Asphalt Pavement[D]. Nanjing: Southeast University,2006.

[16] Luo Rui. Theoretical analysis of the use of the weight function on fatigue cracks in the asphalt pavement expansion[D].Nanjing: Southeast University,2002.

[17]Luo Rui, Huang Xiaoming.Research on the Method to Calculate the Stress Intensity Factor of Asphalt Pavement' s Edge Crack[J].Luo Rui, Huang Xiaoming.Research on the Method to Calculate the Stress Intensity Factor of Asphalt Pavement' s Edge Crack[J]. Journal of Highway and Transportation Research and Development.2002,19(1):12-15.

[18]Zhang Qisen,heng Jianlong, Liu Yihe.Cracking mechanism of semi-rigid asphalt pavement[J].China Civil Engineering Journal.1992,25(2):13-22.

[19]Liu Yihe, Zhang Qisen,Li Zhiyong. Photoelastic study on temperature stress of asphalt pavement[J].China Journal of Highway and Transport.1991,4(4).

[20]Zheng Jianlong, Zhang Qisen.Finite Elements Analysis of Reflection Crack and Stress Intensity Factors in Half Rigid Pavements[J].Chinese Jounal of Geotechnical Engineering.1990,12(3):22-31. 
[21]Wu Gangchang. Analysis of stress intensity factor of crack tip temperature of asphalt pavement[J].China Journal of Highway and Transport.1995,8(2).

[22]Zhou Zhigang, Zhang Qisen. The impact of structural layer combination on crack propagation on the road [J].China Journal of Highway and Transport.1997,10(2):5-10.

[23] Majiedzadeh, K.\& Ramsamooj,D.V., Development of testing Procedures and a method to Predict fatigue failures of asphalt concrete Paving systems. The Ohio State University Research Foundation. Final Report. Project RF 2873. March.1971.

[24]P.D. de Verteuil. Fatigue Properties of Asphaltic Concrete Field Specimens. Ohio State Univ. MS thesis.1973.

[25]J. Rosier, etc. Mixed mode fatigue crack propagation in pavements struetures under traffic load. Reflective Cracking in Pavements. London, 1996.

[26] Schapery, R.A. A theory of Crack growth in viscoelasic media, Report NN-2764-73-1, Mechanics and Material research Center. Texas A\&M University,1973.

[27]A. Vanelstraete, L. Francken. Prevention of Reflective Cracking in Pavement. RILEM Report 18.1997.

[28]R. L. Lytton .Use of geotextiles for reinforcement and strain relief in asphalt concrete. Geotextiles and Geomembranes 8,1989.

[29]A.A.A. Molenaar, M. Nods. Design method for plain and geogrid reinforced overlays on creaked pavements. Reflective Cracking in Pavements. London, 1996.

[30] Ramsamooj. D. v. (1973). Prediction of reflection cracking in Pavement overlays Transportation Research Record.773, 1973.

[31]J. Uzan. Evaluation of fatigue cracking.1997, TRR1570:89-95.

[32]Zhou Zhi gang, Zheng Jian ong, Zhang Qisen. Prediction of Fatigue Cracking Life of Reinforced Asphalt Concrete Pavements. In: Proeeedings of 4th Int. Conf. on Road \& Airfield Pavement Technology, Kunming, 2002.

[33]FREDN. FINN, and CARL L.MONISMITH. Asphalt Overlay Design Procedures, National CooPerativeResearch Program Synthesis of Highway Practice

[34]D. V. Ramsamooj, etc. New anti-reflective cracking pavement overlay design.Reflective Cracking in Pavements. London, 1996, PP.321-330.

[35]Emmanuel B. Owusu- Antwi, etc. Mechanistic- based model for predicting reflective cracking in asphalt concrete- overlaid pavements.1998, TRR 1629:234- 241.

[36]Lytton, RL;Chen, CW;Little, DN, Micordamage Healing In Asphalt And Asphalt Conerete [C], Volume IV:A Viscoelastie Continuum Damage Fatigue - Model of Asphalt Concrete With Micordamage Healing, 2001， 178p

[37] Scarpas, A;Al-Khoury, R;vanGurp, CAPM;Erkens, SMJG, Finte Element Simulation of Damage Development In AsPhalt Conerete pavements[J]，1997， pp673-692

[38]Kim, YR, Fatigue, Performance Evaluation Of Westrack Ans Arizona Sps-9 Mixtures Using Viscoelastic Continuum Damage Pproach[MI, North Carolina State University Department of Civil Engineering, Mann Hall , Box7908, Raleigh NC 27695-27908(peorfmring organization), 1998 
[39]Nilsson, R, Fatigue of Asphalt Mixtures:Continuum Damage Mechanies Applied To Data From Laboratoy Tests[M], 2001, Pag:124P

[40] Shalaby, A.;Easa, S.M.; EI Halim, A.O.Abd, Damage Porpagation In Asphalt Pavements At Low Temperature[C], Sustainable Development, Environment, Geotechnical Engineering, Transportation proceedings, Annual Conefernce-Canadian Society of Civil Engineering v 5 1997.Canadian Soc of Civil Engineering, Montreal, Que, Can. p363-372(source), 1997

[41]Tuskegee, AL.Damage - Evolution Apporach Cracking In Pavements[J], Journal of Engineering Mechanics, 1993, Vol.199, P1243-1258

[42]Zheng Jianlong.[J].Application of Burgers viscoelastic model in the fatigue characteristics analysis of asphalt concrete[J].Journal of Changsha Communication University. 1995,11(3):32-42.

[43] Tang Xuesong, Zheng Jianlong.Damage mechanics integral conservation of reflective cracking problems of asphalt pavement [J]. Chinese Journal of Applied Mechanics.2004,21(2).

[44]Tang Xuesong, Jiang Chiping, Zheng Jianlong.Damaged theories based on irreversible thermodynamics for various damaged materials.Proeeedings of the 4th International Conference on Nonlinear Mechanics.2002

[45] Tang Xuesong, Jiang Chiping, Zheng Jianlong. Anisotropic elastic constitutive erelations of damaged materials by application of irreversible thermodynamics. Theoretical and Applied Fracture Mechanics, 2002，38(3)

[46]Zhou Zhigang.A research on the fatigue damage cracking in asphalt pavement under traffic load[D]. Changsha:Central South University,2003.5.

[47]Ducan,JM.,Chang,C.Y.,Nonlinear analysis of stress and strain in soil[J]. J.Soil Mesh Found.Dive., ASCE,1970,96(5):1629-1652

[48]J.M., Deng Ken, CY. Zhang. Nonlinear analysis of stress and strain in the soil[J].Hydro-Science and Engineering.1973.

[49]Feng Jiaji, Ge Yixiong, Sun Zhaoxiong. Research on stress\&strain characteristics of asphalt concrete[J].Journal of Hydraulic Engineering,1987,11:56-62.

[50] Wang Weibiao, Sun Zhentian, Wu Liyan. Research on stress\&strain characteristics of asphalt concrete[J].Journal of Hydraulic Engineering, 1996.5.

[51] Li Zhiqiang et al . Triaxial test study on mechanical characteristics of asphalt concrete in the core wall of earth-rock fill dam[J].Chinese Journal of Rock Mechanics and Engineering.2006,5.

[52]Liu Hai. Research on constitutive model and experiment of asphalt concrete[D]. Changsha: Defense Technology University. 2007.11.

[53]Lv Songtao, Tian Xiaoge, Zheng Jianlong.Determination of asphalt viscoelastic parameters and its application in the constitutive model[J].Journal of Changsha Communication University. 2005,21(1):37-42.

[54]Qian Guoping, Guo Zhongyin, Zheng Jianlong.Calculation for thermal stresses of asphalt pavement under environmental conditions based on thermal-viscoelasticity theory[J]. Journal of Tongji University. 2003,31(2):150-155.

[55]Zhang Xiaoning,Pan Dalin, Zhu Xiling.One dimensional non-linear viscoelastic constitutive equation of bituminous mixture[J].Chinese Journal of Theoretical and Applied Mechanics.1992,24(6):81-83. 
[56]Zheng Jianglong, Tian Xiaoge, Ying Ronghua. A laboratory research on the thermo-viscoelastic constitutive model of bituminous mixtures[J]. Journal of Changsha University of Science and Technology(Natural Science). 2004,1(1):1-7.

[57] Wang Houyu, Zhu Keshan, Yan Zhixin. A practical model of creep compliance of asphalt concrete and its application[J]. Chinese Journal of Solid Mechanics.2002,23(2):232-236.

[58]Erkens S M J G, Liu X,Scapas A.3D finite element model for asphalt concrete response simulation.2nd International Symposium on 3D Finite Elements in Pavement Engineering, Charleston, West-Virginia, USA, 2000b, Ocotober 11-13

[59]Desai C S, Somasundaram S, Frantziskonis G.A hierarchical approach for constitutive modeling of geologic materials. International Journal of Numerical and analytical Methods in Geomechanics, 1986,10(3):225-257

[60]Cela J. Material identification procedure for elastoplastic Drucker-Prager model.Jounal of Engineering Mechanics,2002,ASCE128(5):586-591

[61]Bousshine L,Chaaba A,De Saxce G.Softening in stress-strain curve for Drucker-Prager non-associated plasticity.International Journal of Plasticity,2001,17:21-46

[62]Laith Tashman, Eyad Masad, Dallas Little, Hussein Zbib. A microstructure-based viscoplastic model for asphalt concrete.. International Journal of Plasticity, 2005 , 21:1659-1685

[63] Vassilis P panoskaltsis, Dinesh Panneerselvam.An anisotropic hyperelastic-viscoplastic damage model for asphalt concrete materials and its numerical implementation. 5th GRACM International Journal of Engineering Science,2000,38:1331-1354

[64] Krishnan J M,Rao C L.Mechanics of air voids reduction of asphalt concrete using mixture theory.International Journal of Engineering Science,2000,38:1331-1354

[65] Hu Xiaodi, Sun Lijun. Analysis of asphalt pavement structure under non-uniform distributed tire pressure with 3D finite element method[J]. Journal of Chang'an University(Natural Science Edition).2003.5.

[66]Liu Dawei et al . Stress Characteristics of Half Rigid Road Under Dynamic Load[J].Journal of Qingdao University(Engineering\&Technology Edition).2006,21(2):59-63.

[67]Feng Jiliang et al. Visco-elastic Method for Prediction of Asphalt Pavement Rutting[J].Journal of Highway and Transportation Research and Development. 2004,21(5):13-14.

[68] Wang Haijun, Li Jing. Finite element analysis of rutted road[J]. Journal of China\&Foreign Highway. 2003,23(6):59-62.

[69]Huang Xiaoming. Boundary element method of layered system of flexible pavement[J].Journal of Chongqing Jiaotong University. 1992,11(3):93-99.

[70] Yue Qiang et al..Linear and nonlinear analysis of stress and displacement fields of layered asphalt pavement.[J]. Chinese Journal of Solid Mechanics.2008,29:64-69.

[71]Chen Jun, Huang Xiaoming. Fatigue performance of asphalt pavement based on discrete element[J].Journal of Harbin Institute of Technology.2009,41(9):100-104.

[72] O'Sullivan C. The application of discrete element modeling to finite deformation problems in geomechanics[D]. Berkeley: University of California, 2002,

[73] Buttlar W G , You Z P. Discrete element modeling of asphalt concrete[C]//TRB. Transportation Research Record 1757. Washington D C: TRB,2001:111-118 
[74] Tang Xuesong, Jiang Chiping, Zheng Jianlong.Mechanical analysis of asphalt mixture fatigue damage process [J]. Chinese Journal of Applied Mechanics.2000,17(4):92-98.

[75] Wang Jinchang, Zhao Yanghua. Fatigue damage analysis of asphalt pavement with reflecting cracks under varying temperature[J]. Chinese Journal of Geotechnical Engineering.2001,23(6):669-671.

[76]Hou Rongguo, Zhao Xiaoping, et al .Structure design and life predicting of long-life pavement[J]. Journal of Chang'an University.2008,28(2):22-25

[77]Luo Hui, Zhu Hongping. Fracture analysis of asphalt pavement based on fatigue life prediction[J]. Journal of China\&Foreign Highway. 2007,24(4):49-52.

[78] Guan Hongxin. A research on viscoelastic fatigue damage model of asphalt mixture[D],Central South University,2005.5.

[79]R. L. Krans, etc. Sem-cireular bending test: a practical crack growth test using asphalt concrete cores. Reflective Cracking in Pavements. London, 1996:123-132. 